\title{
Oxygen delivery to the blood stream by the dialysis fluid during continuous renal replacement therapy ex vivo
}

\author{
Yoshihiro Tange $^{1} \mathbb{D} \cdot$ Shigenori Yoshitake ${ }^{1}$
}

Received: 10 August 2018 / Accepted: 14 December 2018 / Published online: 2 January 2019

(c) The Japanese Society for Artificial Organs 2019

\begin{abstract}
Continuous renal replacement therapy (CRRT) maintains a balance in body water and electrolytes. CRRT supplies a higher quantity of fluid than intravenous fluid therapy along with simultaneous fluid withdrawal. We hypothesized that use of a high-oxygen-containing solution for high-volume fluid exchange would improve oxygenation in the blood during CRRT. To start with, we prepared a solution containing high oxygen. The objective of this study was to determine if this solution would increase the partial pressure of oxygen $\left(\mathrm{O}_{2}\right)$ in the blood more than that using a conventional solution during CRRT. We compared the gas profile of the experimental fluid ex vivo in a simulated CRRT for $24 \mathrm{~h}$, using 2-L batches of bovine blood. A significant increase in the $p \mathrm{O}_{2}, \mathrm{pH}$, and total oxygen delivery, and a significant decrease in the partial pressure of carbon dioxide $\left(p \mathrm{CO}_{2}\right)$ were estimated in the bovine blood using the experimental solution during the simulated CRRT. This method is simpler to apply for oxygenation than the conventional method, and will be beneficial to hypoxic patients in terms of improving their blood oxygenation during CRRT.
\end{abstract}

Keywords Oxygen $\cdot$ Carbon dioxide $\cdot$ Hypoxia $\cdot$ Dialysis fluid $\cdot$ Renal replacement therapy

\section{Introduction}

A ventilator is necessary to improve the hypoxia and hypercarbia in critically ill patients with respiratory failure. Hypoxia occurs when oxygen delivery is insufficient to satisfy the demand in the organs [1]. Continuous renal replacement therapy (CRRT) is used to manage body water, electrolyte and acid-base imbalances in critically ill patients with acute kidney injury (AKI). Patients in the intensive care unit with AKI requiring CRRT have a high risk of early mortality. In these patients, administration of vasopressors and incidence of hypoxia have been independently associated with poor short-term survival [2]. Early initiation of CRRT improves the clinical outcomes in patients with

Yoshihiro Tange

tan@phoenix.ac.jp

Shigenori Yoshitake

systk@phoenix.ac.jp

1 Department of Medical Engineering, Kyushu University of Health and Welfare, 1714-1 Yoshinomachi, Nobeoka, Miyazaki 8828508, Japan acute respiratory distress syndrome (ARDS) [3], and there has been a recent report about high-volume CRRT improving blood oxygenation in patients with severe ARDS [4]. Further, in an animal model of septic shock, high-volume hemofiltration improved the partial pressure of oxygen $\left(p \mathrm{O}_{2}\right)$ and preserved pulmonary vascular permeability [5]. These studies highlight the importance of ameliorating hypoxia in critically ill patients requiring CRRT. However, the mechanism by which the hypoxia is induced in the patients depends on multiple factors and has been unknown.

An increment in the $p \mathrm{O}_{2}$ estimated following a conventional intermittent hemodialysis (HD) has been attributed to the $p \mathrm{O}_{2}$ in the dialysis fluid being higher than that in the patient's blood [6]. This finding suggests that improvement of blood oxygenation in patients with hypoxia depends not only on the removal of fluid overload, but also on a higher $p \mathrm{O}_{2}$ in the supplemental fluid.

We developed a solution saturated with dissolved oxygen using a simple method, and observed increases in the $p \mathrm{O}_{2}$ and total oxygen content $\left(\mathrm{CaO}_{2}\right)$ in the blood in vitro using this solution [7]. Applying this method to the supplemental bicarbonate dialysis fluid, a significant increase in the $p \mathrm{O}_{2}$ and simultaneous decrease in the partial pressure of carbon 
dioxide $\left(p \mathrm{CO}_{2}\right)$ were observed [8]. Gehlbach et al. suggested that an intravenous (IV) supersaturated solution might also improve hypoxia in critically ill patients with respiratory failure [9].

The objective of this study was to test the hypothesis whether a saturated oxygen solution would increase the $p \mathrm{O}_{2}$ in the circulating blood to a greater degree than a conventional solution during a simulated CRRT. Using the experimental solution, we performed a CRRT simulation for $24 \mathrm{~h}$ using bovine blood, and determined the blood gas profiles ex vivo.

\section{Materials and methods}

\section{Bovine blood}

Batches of bovine blood with a hematocrit of $30 \%$ were obtained from a local supplier (Miyazaki Beef Provider, Nobeoka, Japan); 3.8\% sodium citrate (Wako Pure Chemical Industries, Ltd., Osaka, Japan) and 4000 units of heparin (Fuso Chemical Co., Ltd., Osaka, Japan) were used as anticoagulants. The baseline $p \mathrm{O}_{2}$ was measured by the blood gas analyzer (i-STAT, 300F; Abbott Laboratories, Chicago, IL, USA) using an analytical cartridge for blood gas (EG6 + cartridge, Abbott Laboratories, Chicago, IL, USA), which estimated the $p \mathrm{O}_{2}$ to be approximately $40 \mathrm{mmHg}$ in the bovine blood before the experiment.

\section{Supplemental fluid}

We prepared a sample of conventional supplemental fluid (Sublood-BSG, Fuso Chemical Industries, Ltd., Osaka, Japan), and removed the air in it using a syringe (NIPRO Medical Corp., Osaka, Japan) and shaking for 1 min manually. We then injected oxygen gas into the fluid using a syringe. Oxygen gas was obtained from an oxygen piping line. The amount of oxygen injected into the $2020 \mathrm{~mL}$ of supplemental fluid was $1000 \mathrm{~mL}$. The bags were shaken for $1 \mathrm{~min}$ and placed on a table until the bubbles diminished visually. Differences of study solution from conventional fluid are whether oxygen gas injected or not. Also, these solutions of gas profiles were measured by an i-STAT.

\section{Determination of blood gas analysis profiles ex vivo}

Schematic representation of simulated CRRT is shown in Fig. 1. Six polysulfone hemofilters (AEF-10, Asahi-Kasei Pharma, Tokyo, Japan) were used in total. Conventional supplemental fluid was set as the control solution and the oxygen-containing experimental supplemental fluid was set as the study solution. Simulated continuous hemodiafiltration (CHDF; one of the techniques used for CRRT) was performed for $24 \mathrm{~h}$ using either the experimental fluid as the study solution or the conventional fluid as control solution, delivered by a blood pump at a flow rate of $100 \mathrm{~mL} / \mathrm{min}$. The dialysis fluid was delivered at a flow rate of $900 \mathrm{~mL} / \mathrm{h}$ with a filtration and supplemental flow rate of $300 \mathrm{~mL} / \mathrm{h}$ in a post-dilution mode. The bovine blood volume was $2000 \mathrm{~mL}$, and the blood temperature was set at $37{ }^{\circ} \mathrm{C}$ during the experiment. The $p \mathrm{O}_{2}$, $p \mathrm{CO}_{2}, \mathrm{pH}$, hemoglobin $(\mathrm{Hb})$, and oxygen saturation $\left(\mathrm{SO}_{2}\right)$ values obtained from the bovine blood via the sampling port before the hemofiltration were measured by an i-STAT. The samples were obtained at time zero as the baseline and up to $24 \mathrm{~h}$. The value of $\mathrm{CaO}_{2}$ and oxygen delivery $\left(\mathrm{DO}_{2}\right)$ was calculated using the following formula:

$$
\mathrm{C}_{\mathrm{a}} \mathrm{O}_{2}[\mathrm{~mL} / \mathrm{dL}]=\mathrm{Hb} \times 1.34 \times\left(\frac{\mathrm{SO}_{2}}{100}\right)+0.003 \times \mathrm{PO}_{2},
$$

Fig. 1 Schematic representation of simulated continuous renal replacement therapy ex vivo. Simulated continuous hemodiafiltration was performed using a conventional supplemental fluid or an oxygen-injected supplemental fluid

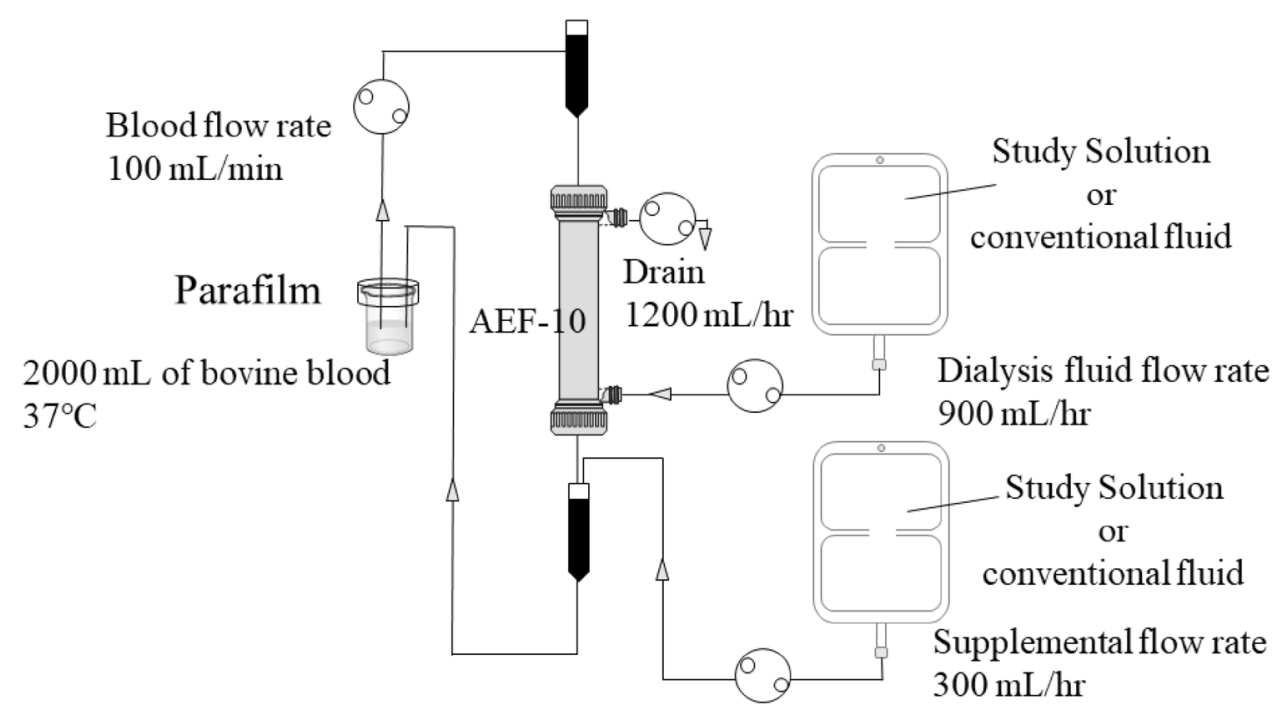


$\mathrm{DO}_{2}[\mathrm{~mL} / \mathrm{min}]=\mathrm{C}_{\mathrm{a}} \mathrm{O}_{2} \times 0.1 \times 10$.

\section{Statistical analysis}

Statistical analyses were completed using a GraphPad Prism 7.05 (GraphPad Software, Inc., La Jolla, CA, USA). Continuous variables were described as the mean \pm standard deviation (SD). Interaction was discriminated by two-way repeated measures analysis of variance (ANOVA) and oneor two-way ANOVA were used with Tukey's multiple comparisons test.

\section{Results}

The $p \mathrm{O}_{2}, p \mathrm{CO}_{2}$, and $\mathrm{pH}$ in the conventional fluid and study solution before use were $103 \pm 6$ and $517 \pm 11 \mathrm{mmHg}$ in $p \mathrm{O}_{2}$, $96 \pm 10 \mathrm{mmHg}, 67 \pm 3 \mathrm{mmHg}$ in $p \mathrm{CO}_{2}$ and $7.15 \pm 0.04$ and $7.36 \pm 0.02$ in $\mathrm{pH}$, respectively $(P<0.01)$.

Table 1 shows the changes in the blood gas profiles during the CHDF. There were significant increases in the $p \mathrm{O}_{2}$ in the study solutions after $540 \mathrm{~min}$ vs. that at the baseline $(P<0.01)$. The mean $p \mathrm{O}_{2}$ values in the blood at the baseline in the study and control groups were $41 \pm 8$ and $36 \pm 9 \mathrm{mmHg}$, respectively. The mean $p \mathrm{O}_{2}$ values in the study group were significantly higher than that in the control group at $9 \mathrm{~h}(136 \pm 67 \mathrm{vs} .43 \pm 6 \mathrm{mmHg}, P<0.01), 12 \mathrm{~h}$ $(198 \pm 80$ vs. $44 \pm 5 \mathrm{mmHg}, P<0.01)$, and $24 \mathrm{~h}(290 \pm 12$ vs. $43 \pm 3 \mathrm{mmHg}, P<0.01)$, respectively.
There were significant increases in the $p \mathrm{CO}_{2}$ in control and study solutions after 45 and $120 \mathrm{~min}$ vs. that at the baseline, respectively $(P<0.01)$. The mean $p \mathrm{CO}_{2}$ values in the blood at the baseline in the study and control groups were $48 \pm 2$ and $47 \pm 3 \mathrm{mmHg}$, respectively. The mean $p \mathrm{CO}_{2}$ values during the CHDF were significantly lower in the study group than that in the control group at $3 \mathrm{~h}(70 \pm 2$ vs. $84 \pm 6 \mathrm{mmHg}, P<0.05), 6 \mathrm{~h}(77 \pm 3$ vs. $95 \pm 4 \mathrm{mmHg}$, $P<0.01), 9$ h $(76 \pm 5$ vs. $95 \pm 3 \mathrm{mmHg}, P<0.01), 12 \mathrm{~h}$ $(71 \pm 1$ vs. $97 \pm 4 \mathrm{mmHg}, P<0.01)$, and $24 \mathrm{~h}(70 \pm 1$ vs. $94 \pm 0 \mathrm{mmHg}, P<0.01$ ), respectively.

There was a significant decrease in the $\mathrm{pH}$ level of the control solution after $180 \mathrm{~min}$ vs. that at the baseline $(P<0.01)$. The mean $\mathrm{pH}$ levels of the blood at the baseline in the study and control groups were $7.29 \pm 0.03$ and $7.31 \pm 0.03$, respectively. During the CHDF, the mean $\mathrm{pH}$ values were significantly higher in the study group than that in the control group at $6 \mathrm{~h}(7.25 \pm 0.00$ vs. $7.15 \pm 0.02$, $P<0.01), 9$ h $(7.25 \pm 0.03$ vs. $7.14 \pm 0.01, P<0.01), 12 \mathrm{~h}$ $(7.29 \pm 0.02$ vs. $7.14 \pm 0.02, P<0.01)$, and $24 \mathrm{~h}(7.28 \pm 0.04$ vs. $7.15 \pm 0.00, P<0.01$ ), respectively.

Table 2 shows the changes in the $\mathrm{DO}_{2}$ values during the CHDF. The mean $\mathrm{DO}_{2}$ values in the blood at the baseline in the study and control groups were $8.4 \pm 2.1 \mathrm{~mL} / \mathrm{min}$ and $7.8 \pm 2.6 \mathrm{~mL} / \mathrm{min}$, respectively. During the CHDF, the mean $\mathrm{DO}_{2}$ values were significantly higher in the study group than that in the control group at $6 \mathrm{~h}(11.5 \pm 2.0 \mathrm{vs} .8 .7 \pm 1.9 \mathrm{~mL} /$ $\mathrm{min}, P<0.01), 9 \mathrm{~h}(12.3 \pm 1.8$ vs. $8.0 \pm 1.3 \mathrm{~mL} / \mathrm{min}$, $P<0.01), 12$ h $(13.1 \pm 1.5$ vs. $8.0 \pm 1.6 \mathrm{~mL} / \mathrm{min}, P<0.01)$, and $24 \mathrm{~h}(13.4 \pm 1.3$ vs. $7.5 \pm 0.8 \mathrm{~mL} / \mathrm{min}, P<0.01)$,

Table 1 Changes in the blood gas profiles during simulated continuous hemodiafiltration

\begin{tabular}{|c|c|c|c|c|c|c|c|c|c|}
\hline \multirow[t]{2}{*}{ Time (min) } & \multicolumn{2}{|l|}{$p \mathrm{O}_{2}(\mathrm{mmHg})$} & \multirow[t]{2}{*}{$P$ values } & \multicolumn{2}{|l|}{$p \mathrm{CO}_{2}(\mathrm{mmHg})$} & \multirow[t]{2}{*}{$P$ values } & \multicolumn{2}{|l|}{$\mathrm{pH}(-)$} & \multirow[t]{2}{*}{$P$ values } \\
\hline & $\begin{array}{l}\text { Control solu- } \\
\text { tion }\end{array}$ & Study solution & & $\begin{array}{l}\text { Control solu- } \\
\text { tion }\end{array}$ & Study solution & & $\begin{array}{l}\text { Control solu- } \\
\text { tion }\end{array}$ & Study solution & \\
\hline 0 & $36 \pm 9$ & $41 \pm 8$ & NS & $47 \pm 3$ & $48 \pm 2$ & NS & $7.31 \pm 0.03$ & $7.29 \pm 0.03$ & NS \\
\hline 15 & $35 \pm 6$ & $40 \pm 10$ & NS & $52 \pm 3$ & $52 \pm 3$ & NS & $7.30 \pm 0.03$ & $7.30 \pm 0.03$ & NS \\
\hline 30 & $37 \pm 7$ & $41 \pm 9$ & NS & $57 \pm 1$ & $54 \pm 3$ & NS & $7.29 \pm 0.03$ & $7.29 \pm 0.03$ & NS \\
\hline 45 & $38 \pm 7$ & $44 \pm 9$ & NS & $62 \pm 2 * *$ & $58 \pm 2^{*}$ & NS & $7.28 \pm 0.02$ & $7.29 \pm 0.03$ & NS \\
\hline 60 & $38 \pm 6$ & $45 \pm 12$ & NS & $65 \pm 4 * *$ & $57 \pm 2$ & NS & $7.27 \pm 0.01$ & $7.30 \pm 0.04$ & NS \\
\hline 120 & $41 \pm 8$ & $47 \pm 10$ & NS & $77 \pm 7 * *$ & $66 \pm 2 * *$ & NS & $7.24 \pm 0.02$ & $7.28 \pm 0.02$ & NS \\
\hline 180 & $42 \pm 7$ & $53 \pm 12$ & NS & $84 \pm 6^{* *}$ & $70 \pm 2 * *$ & $P<0.05$ & $7.20 \pm 0.02 * *$ & $7.26 \pm 0.02$ & NS \\
\hline 360 & $45 \pm 8$ & $71 \pm 21$ & NS & $95 \pm 4 * *$ & $77 \pm 3 * *$ & $P<0.01$ & $7.15 \pm 0.02 * *$ & $7.25 \pm 0.00$ & $P<0.01$ \\
\hline 540 & $43 \pm 6$ & $136 \pm 67 * *$ & $P<0.01$ & $95 \pm 3 * *$ & $76 \pm 5 * *$ & $P<0.01$ & $7.14 \pm 0.01 * *$ & $7.25 \pm 0.03$ & $P<0.01$ \\
\hline 720 & $44 \pm 5$ & $198 \pm 80 * *$ & $P<0.01$ & $97 \pm 4 * *$ & $71 \pm 1 * *$ & $P<0.01$ & $7.14 \pm 0.02 * *$ & $7.29 \pm 0.02$ & $P<0.01$ \\
\hline 1440 & $43 \pm 3$ & $290 \pm 12 * *$ & $P<0.01$ & $94 \pm 0 * *$ & $70 \pm 1 * *$ & $P<0.01$ & $7.15 \pm 0.00^{* *}$ & $7.28 \pm 0.04$ & $P<0.01$ \\
\hline
\end{tabular}

The data are shown as the mean \pm standard deviation of $n=3$

Time 0 is the time before the start of CRRT, and the rest show the time after the beginning of CRRT

$N S$ not statistically significant

$* P<0.05$ vs. baseline (time: 0 )

$* * P<0.01$ vs. baseline (time: 0 ) 
Table 2 Changes in the total oxygen delivery during simulated continuous hemodiafiltration

\begin{tabular}{llll}
\hline Time $[\mathrm{min}]$ & $\mathrm{DO}_{2}[\mathrm{~mL} / \mathrm{min}]$ & $P$ values \\
\cline { 2 - 3 } & Control solution & Study solution & \\
\hline 0 & $7.8 \pm 2.6$ & $8.4 \pm 2.1$ & $\mathrm{NS}$ \\
15 & $7.8 \pm 2.2$ & $8.2 \pm 2.6$ & $\mathrm{NS}$ \\
30 & $7.9 \pm 2.5$ & $8.6 \pm 2.7$ & $\mathrm{NS}$ \\
45 & $8.2 \pm 2.3$ & $9.2 \pm 2.3$ & $\mathrm{NS}$ \\
60 & $8.5 \pm 2.1$ & $9.5 \pm 2.9$ & $\mathrm{NS}$ \\
120 & $8.9 \pm 2.1$ & $9.7 \pm 2.3$ & $\mathrm{NS}$ \\
180 & $8.7 \pm 2.1$ & $10.5 \pm 2.3^{*}$ & $\mathrm{NS}$ \\
360 & $8.7 \pm 1.9$ & $11.5 \pm 2.0^{* *}$ & $P<0.01$ \\
540 & $8.0 \pm 1.3$ & $12.3 \pm 1.8^{* *}$ & $P<0.01$ \\
720 & $8.0 \pm 1.6$ & $13.1 \pm 1.5^{* *}$ & $P<0.01$ \\
1440 & $7.5 \pm 0.8$ & $13.4 \pm 1.3^{* *}$ & $P<0.01$ \\
\hline
\end{tabular}

The data are shown as the mean \pm standard deviation of $n=3$

$N S$ not statistically significant

$* P<0.05$ vs. baseline (time: 0 )

$* * P<0.01$ vs. baseline (time: 0 )

respectively. There was a significant increase in the $\mathrm{DO}_{2}$ values in the study solution at $180 \mathrm{~min}(P<0.05)$, and after 360 min vs. that at the baseline $(P<0.01)$.

\section{Discussion}

We could validate the hypothesis that a saturated oxygen solution would increase the $p \mathrm{O}_{2}$ in the circulating blood during a simulated CRRT to a greater degree than a conventional solution. We demonstrated that the $p \mathrm{O}_{2}$ and $\mathrm{DO}_{2}$ in the blood increase significantly using a saturated oxygen solution. Our findings supported the results of the previous studies $[7,10,11]$.

Critically ill patients with hypoxia need blood oxygenation. Preparing saturated oxygen solutions has been considered difficult because of the need of original devices [10-12]. However, we developed a saturated oxygen solution using a simple method [7]. This method resulted in the increase in the $p \mathrm{O}_{2}$ more than $500 \mathrm{mmHg}$. This value is equivalent to or a little less than the values reported in other studies [10-12] that have used the methods different from the one used in the present study.

Blood oxygenation methods that involve using solutions containing micro/nanobubbles always carry a risk of an air embolus; but, our method simply involved dissolving oxygen in the solution. The inner pressure in the bag was measured by a portable manometer (PG-100; NIDEC COPAL ELECTRONICS, Inc., Iruma, Japan) prior to sampling the solution. There was not any pressure in the bag since the bag was not swollen after gas was injected.
Pressures of conventional fluid and study solution showed $0 \mathrm{kPa}$ on table and $1.7 \mathrm{kPa}$ in outlet pressure in suspended state. From the standpoint of medical safety and medical engineering, burst of package, explosion or pump malfunction due to high pressure on tubing by injecting oxygen gas into fluid bags was not observed and resulted in less chance of incident/accident.

The oxygen delivery was very smaller in this study than that in adult because of less flow volume. However, it would be beneficial for pediatric patients with hypoxia. ECMO is a good method to provide strong oxygenation which is a complicated and expensive treatment. This study demonstrated simple and less expensive method to supply oxygen even if the oxygen delivery is small. Much efforts including man power are made during ECMO treatment. Switching oxygen membrane is the critical procedure when the membrane deteriorates. CRRT is able to simultaneously withdraw the body fluid. Using study solution would be beneficial in the patients during CRRT. We think that CRRT using this study solution would be difficult for complete alternative of ECMO. However, Lieberman et al. described that critical oxygen delivery in conscious humans is less than $7.3 \mathrm{~mL}$ oxygen $/ \mathrm{kg} / \mathrm{min}$ [13]. Therefore, this method should be studied in vivo model of hypoxemia. A previous study on juvenile swine demonstrated a significant increase in the $p \mathrm{O}_{2}$ from 78 to $94 \mathrm{mmHg} 1 \mathrm{~h}$ after the injection of a cold supersaturated oxygen solution (at a $p \mathrm{O}_{2}: 992 \mathrm{mmHg}$ ) administered by an IV infusion [14]. The mean body weight of the animals in that study was $12.9 \mathrm{~kg}$, and the IV infusion volume was calculated to be $390 \mathrm{~mL}$ per hour, although the IV flow rate in that study was different from that of $1200 \mathrm{~mL}$ per hour used in our present study. There was still a significant increase in the $p \mathrm{O}_{2}$ in the blood. Further, in our study, the $p \mathrm{CO}_{2}$ in the bovine blood had lowered with an infusion of the oxygenated solution than that with infusion of the conventional solution. We speculated that carbon dioxide $\left(\mathrm{CO}_{2}\right)$ in the solution moved to gas portion by diffusion after the injection of oxygen gas into the supplemental fluid. This mechanism is similar to that of the artificial lungs in the cardiopulmonary bypass. It means that with the increase in the injected oxygen gas volume, the $p \mathrm{CO}_{2}$ value in the solution decreases.

Initial $p \mathrm{O}_{2}$ of conventional fluid shows $103 \pm 6 \mathrm{mmHg}$. The $p \mathrm{O}_{2}$ at baseline in blood showed hypoxia of $40 \mathrm{mmHg}$. We wrapped a beaker $(2000 \mathrm{~mL})$ with the Parafilm (Bemis Co., Inc., USA). This condition simulated in the state of respiratory failure because $p \mathrm{O}_{2}$ in the blood did not increased with time. Therefore, $p \mathrm{CO}_{2}$ went up gradually and reached out to $94 \mathrm{mmHg}$. We speculated that this condition depending on fluid gas profiles. In addition, bicarbonate in the supplemental solution easily dissociates into $\mathrm{CO}_{2}$ and $\mathrm{H}_{2} \mathrm{O}$. Therefore, $p \mathrm{CO}_{2}$ in the blood increased using conventional fluid. 
Recently, $\mathrm{CO}_{2}$ removal using lactic acid and hydrochloric acid at a low blood flow during the CRRT has been reported [15]. Their study demonstrated the mechanism of $\mathrm{CO}_{2}$ removal using acids, with a membrane lung incorporated in a CHDF system at a low blood flow. In an ex vivo study, the amount of $\mathrm{CO}_{2}$ removal using their system was reported to be more than twice of that from using conventional techniques. We showed gradual increases in the $p \mathrm{CO}_{2}$ in the blood using the experimental solution, but significantly lower than that with the control solution. Our saturated oxygen solution may not only be used for blood oxygenation, but also for $\mathrm{CO}_{2}$ removal. However, these results suggest that, although a perfect alternative to artificial lungs, it is difficult to say from the view point of blood flow rate and $\mathrm{CO}_{2}$ removal that if this method is used for oxygenation in hypoxic patients with respiratory failure, it would promisingly result in higher $p \mathrm{O}_{2}$ and lower $p \mathrm{CO}_{2}$ in the blood stream in contrast to that from using the conventional methods.

As for the solute removal efficacy, we set $900 \mathrm{~mL} / \mathrm{h}$ $(15 \mathrm{~mL} / \mathrm{min})$ of dialysis fluid flow in this experiment. Therefore, maximum clearance is lower than $15 \mathrm{~mL} / \mathrm{min}$. We could not find any bubbles in the filter visually during this experiment and that did not influence membrane clearance.

We conducted preliminary experiments with post-dilution HDF. The $p \mathrm{O}_{2}$ was determined in single-pass method using bovine blood. The $p \mathrm{O}_{2}$ in the arterial side was $46 \pm 1 \mathrm{mmHg}$. The $p \mathrm{O}_{2}$ in the venous side in $\mathrm{HD}$ and post-dilution HDF was $74 \pm 2$ and $86 \pm 4 \mathrm{mmHg}$, respectively $(n=3, P<0.05)$. We suggested that study solution was more effective to use for HDF than HD fluid for blood oxygenation. In addition, pre-dilution HDF is able to supply high volume fluid. We also conducted preliminary experiments regarding blood oxygenation. We conducted pre-dilution and post-dilution mode using study solution by bovine blood. Experiments were set at $30 \mathrm{~mL} / \mathrm{min}$ of blood flow and $60 \mathrm{~mL} / \mathrm{min}$ of dialysis fluid flow. Supplemental flow rates were set at 10, 30 and $60 \mathrm{~mL} / \mathrm{min}$ in the pre-dilution HDF, and at $10 \mathrm{~mL} /$ min in the post-dilution HDF. Arterial and venous sides of $p \mathrm{O}_{2}$ in bovine blood were determined by i-STAT. The $p \mathrm{O}_{2}$ in the arterial side was $44 \pm 4 \mathrm{mmHg}$. The $p \mathrm{O}_{2}$ in the venous side was $66 \pm 13 \mathrm{mmHg}$ in $\mathrm{HD}$, and increased to $93 \pm 27$, $122 \pm 57,183 \pm 63 \mathrm{mmHg}$ in 10,30 , and $60 \mathrm{~mL} / \mathrm{min}$ of pre-dilution HDF, respectively and $76 \pm 17 \mathrm{mmHg}$ in postdilution HDF. Smaller area of hemofilter $\left(0.3 \mathrm{~m}^{2}\right)$ (AEF-03, Asahi-Kasei Pharma, Tokyo, Japan) was used in this study because of simulated pediatric patients. If these results are applied for critically ill patients, high volume pre-dilution CHDF for blood oxygenation is promising. High-volume pre-dilution CHDF using study solution is a better mode for blood oxygenation. Our final goal of this study is improving systemic hypoxia in ARDS. To improve our method getting closer to ECMO, it will need not only increased blood flow volume but also increased dialysis flow volume with highvolume pre-dilution mode. Our fluid oxygenation method is very simple, and will also apply for other solutions such as priming and intravenous fluid.

This study has limitations. It was an experimental ex vivo study that did not consider oxygen consumption and $\mathrm{CO}_{2}$ production. If this method is applied in clinical practice, the differences in both the solutions may not be obvious. However, we demonstrated high oxygen delivery to the blood stream from the dialysis fluid containing highly saturated oxygen by comparing with conventional fluid in simulation model.

\section{Conclusions}

We prepared a saturated oxygen solution that enables a significant increase in the partial pressure of oxygen and oxygen delivery, and a significant decrease in the partial pressure of carbon dioxide in contrast to that achieved from using the conventional solution for continuous hemodiafiltration. Compared to the conventional solution, this solution can deliver a significant amount of oxygen from the dialysis fluid to the blood stream.

Acknowledgements The authors would like to thank all the colleagues who helped with our experiments.

Funding This research has not received any specific grant from any funding agencies in public, commercial, or not-for-profit sectors.

\section{Compliance with ethical standards}

Conflict of interest The authors report no proprietary or commercial interest for any product mentioned or any concept discussed in this article.

\section{References}

1. Henig NR, Pierson DJ. Mechanisms of hypoxemia. Respir Care Clin N Am. 2000;6:501-21.

2. Prasad B, Urbanski M, Ferguson TW, Karreman E, Tangri N. Early mortality on continuous renal replacement therapy (CRRT): the Prairie CRRT study. Can J Kidney Health Dis. 2016;3:36.

3. Han F, Sun R, Ni Y, et al. Early initiation of continuous renal replacement therapy improves clinical outcomes in patients with acute respiratory distress syndrome. Am J Med Sci. 2015;349:199-205.

4. Yang W, Hong J, Zeng Q, et al. Improvement of oxygenation in severe acute respiratory distress syndrome with high-volume continuous veno-venous hemofiltration. Glob Pediatr Health. 2016. https://doi.org/10.1177/2333794X16645699.

5. Zhao P, Zheng R, Xue L, Zhang M, Wu X. Early fluid resuscitation and high volume hemofiltration decrease septic shock progression in swine. Biomed Res Int. 2015;2015:181845. 
6. Sombolos KI, Bamichas GI, Christidou FN, et al. $p \mathrm{O} 2$ and $p \mathrm{CO} 2$ increment in post-dialyzer blood: the role of dialysate. Artif Organs. 2005;29:892-8.

7. Tange Y, Yoshitake S, Takesawa S. Simple method to make a supersaturated oxygen solution. J Artif Organs. 2018;21:392-5.

8. Tange $\mathrm{Y}$, Yoshitake $\mathrm{S}$. Data on a simple method for producing a solution that contains a high partial pressure of oxygen and a low partial pressure of carbon dioxide. Data Brief. 2018;18:176-9.

9. Gehlbach JA, Rehder KJ, Gentile MA, et al. Intravenous oxygen: a novel method of oxygen delivery in hypoxemic respiratory failure. Expert Rev Respir Med. 2017;11:73-80.

10. Matsuki N, Ishikawa $T$, Ichiba $S$, et al. Oxygen supersaturated fluid using fine micro/nanobubbles. Int J Nanomed. 2014;9:4495-505.

11. Tange Y, Migita H, Yoshitake S, et al. Dialysate with High Partial Pressure of oxygen enhances oxygenation in blood during simulated circulation of hemodialysis. Adv Biomed Eng. 2012;1:43-6.

12. Xu H, Li Y, Gao W, Zhang H, Xu LX. Hyperoxygenated solutions in clinical practice: Preventing or reducing hypoxic injury. J Int Med Res. 2011;39:1589-606.
13. Lieberman JA, Weiskopf RB, Kelly SD, et al. Critical oxygen delivery in conscious humans is less than $7.3 \mathrm{ml} \mathrm{O} 2 \times \mathrm{kg}(-1) \mathrm{x}$ $\min (-1)$. Anesthesiology. 2000;92: 407-13.

14. Grady DJ, Gentile MA, Riggs JH, Cheifetz IM. Improved arterial blood oxygenation following intravenous infusion of cold supersaturated dissolved oxygen solution. Clin Med Insights Circ Respir Pulm Med. 2014;8:11-6.

15. Takahashi N, Nakada T, Oda S. Efficient $\mathrm{CO}_{2}$ removal using extracorporeal lung and renal assist device. J Artif Organs. 2018;21:427-34.

Publisher's Note Springer Nature remains neutral with regard to jurisdictional claims in published maps and institutional affiliations. 